Revista de
Economida
Contemporâned

\title{
REGIME DE METAS DE INFLAÇÃO: ANÁLISE COMPARATIVA E EVIDÊNCIAS EMPÍRICAS PARA PAÍSES EMERGENTES SELECIONADOS
}

\author{
Mateus Ramalho Ribeiro da Fonseca ${ }^{a}$ \\ Samuel Costa Peres ${ }^{b}$ \\ Eliane Cristina de Araújoc

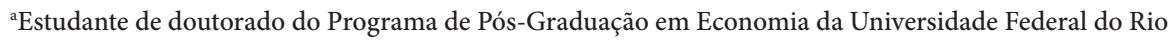 \\ Grande do Sul (PPGE/UFRGS) e bolsista CAPES.

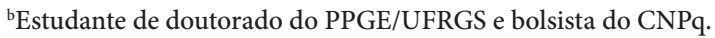 \\ 'Professora do Departamento de Economia da Universidade Estadual de Maringá (UEM) \\ e bolsista de produtividade do CNPq. \\ Artigo recebido em 20/02/2014 e aceito em 23/02/2016.
}

RESUMO: O objetivo deste artigo é analisar o regime de metas de inflação (RMI) no Brasil à luz das experiências de outros países emergentes selecionados, quais sejam: África do Sul, Chile, Colômbia, Coreia do Sul e México. Para tanto, há uma exposição dos contextos nos quais o RMI foi adotado nesses países, bem como uma comparação entre os arranjos desses regimes, para se distinguir suas principais características. Por fim, é estimado um modelo autorregressivo com vetores de correção de erros (VEC) para cada país selecionado, de modo a criar condições para uma análise da eficácia do RMI nessas economias. Os resultados empíricos da pesquisa sugerem que os Regimes de Metas de inflação mais flexíveis (África do Sul, Chile, Colômbia, Coreia do Sul) são relativamente mais eficazes em termos de combate à inflação que os regimes mais rígidos (Brasil e México).

PALAVRAS-CHAVE: inflação; regime de metas de inflação; modelo VEC.

CLASSIFICAÇÃO JEL: E42; E52; C32.

Correspondência para: Mateus Ramalho Ribeiro da Fonseca

Contato: mateusramalho88@hotmail.com 


\title{
INFLATION TARGETING REGIME: COMPARATIVE ANALYSIS AND EMPIRICAL EVIDENCE FOR SELECTED EMERGING COUNTRIES
}

\begin{abstract}
The objective of this paper is to analyze the inflation targeting regime (ITR) in Brazil in the light of the experiences of other selected emerging countries, namely: South Africa, Chile, Colombia, South Korea and Mexico. To that end, there is an exposition of the contexts in which ITR was adopted in the selected countries, as well as a comparison between the arrangements of these regimes, to distinguish its main features. Lastly, an autoregressive model is estimated with vector error correction (VEC) for each country in the sample, in order to set the conditions for an analysis of the efficiency of ITR in these economies. The empirical results of the research suggest that the most flexible inflation targeting regimes (South Africa, Chile, Colombia, South Korea) are relatively more efficient in terms of curbing inflation than more rigid regimes (Brazil and Mexico).
\end{abstract}

KEYWORDS: inflation; inflation targeting; VEC model. 


\section{INTRODUÇÃO}

As transformações ocorridas no campo das decisões de políticas econômicas nas últimas décadas atentaram para o papel da estabilidade macroeconômica no desempenho das economias de mercado, em que o controle inflacionário constituiu-se como objetivo principal das autoridades monetárias.

Diante das frustrações e problemas acumulados com as tentativas de controle monetário e conhecidos os ônus da ancoragem cambial, a estratégia de política monetária denominada meta inflacionária, já empregada com sucesso em países desenvolvidos como Nova Zelândia (1990), Canadá (1991), Reino Unido (1992) e Austrália (1994), tornou-se uma alternativa atrativa para os países emergentes. O Chile em 1990 foi o primeiro emergente a adotar (informalmente) o regime de metas de inflação (RMI) como estratégia de política monetária. Esse movimento foi acompanhado em seguida por outros países como a Polônia (1998), Brasil (1999), México (1999) e África do Sul (2000). Com efeito, desde a adoção do regime de metas, esses países têm logrado êxito na manutenção da estabilidade de preços. No entanto, apesar dos resultados satisfatórios em termos de estabilidade de preços, as diferentes formas de condução da política monetária nesses países suscitam dúvidas no que tange ao perfil do regime adotado pelo Brasil, cuja rigidez tem implicado um elevado custo social, com altas taxas de juros e baixo crescimento econômico.

Portanto, analisar o RMI no Brasil à luz das experiências de outros países (em especial, os emergentes) torna-se importante para o processo de aperfeiçoamento do modelo vigente no país. Nesse sentido, objetiva-se neste artigo contrastar o RMI brasileiro com os regimes utilizados por alguns países emergentes selecionados, quais sejam: África do Sul, Chile, Colômbia, Coreia do Sul e México. No intuito de se comparar o desempenho do Brasil com o de outros países da América Latina, e de ao menos um da África e um da Ásia, a escolha pelos países supracitados se deve, em primeiro lugar, ao fato de o período de adoção do RMI ser muito próximo, entre 1998 e 2000, o que estatisticamente torna a comparação de dados mais uniforme e eficaz. Em segundo lugar, com exceção da Coreia do Sul, esses países possuem rendas médias relativamente próximas e estão em processo de desenvolvimento, o que torna a comparação mais interessante. Ademais, o fato de a África do Sul estar ao lado do Brasil no grupo dos BRICS também sugestiona a inclusão deste país. No caso da Coreia do Sul, sua inclusão se justifica por ser um país de industrialização recente, como Brasil, México e África do Sul, mas que foi bem-sucedido no seu processo de catching-up (emparelhamento) com os países desenvolvidos ${ }^{1}$, o que enriquece a análise do ponto de vista

1 Sobre a bem-sucedida trajetória de catching-up da Coreia do Sul, ver, por exemplo, Amsden (1989). 
de lições que podem ser apreendidas. Desse modo, a amostra procura abranger países de características semelhantes em termos de desenvolvimento econômico, tendo em vista que a comparação com países desenvolvidos (como Nova Zelândia, Canadá, Suécia etc.) poderia enviesar a análise comparativa, tanto estatística quanto analiticamente, para conclusões precipitadas no que diz respeito à eficácia do RMI em termos de controle inflacionário.

$\mathrm{O}$ artigo divide-se em quatro seções, além dessa introdução e de uma conclusão. Na segunda seção são apresentados os contextos nos quais o RMI foi adotado nos países selecionados. Na sequência são distinguidas as características desse regime entre os países selecionados. Na seção quatro é estimado um modelo autorregressivo com correção de erros (VEC) para cada país selecionado, de modo a criar condições para uma análise da eficácia desse regime nessas economias, que é a proposta da seção subsequente. Por fim, um esforço de conclusão encerra este artigo.

\section{CONTEXTO DE ADOÇÃO DO RMI NOS PAÍSES SELECIONADOS}

\section{1. ÁFRICA DO SUL}

Entre os anos 1980 e início dos 1990, a África do Sul conviveu com taxas de inflação bastante elevadas, sendo a média do período de aproximadamente 15\%. A partir de 1993, a inflação no país entrou em tendência declinante, sendo a média inferior a $8 \%$ entre essa data e o ano de 1999. Ressalta-se que a partir de março de 1998 o Banco Central do país passou a utilizar um grupo de indicadores econômicos com o intuito de balizar as decisões de política monetária. Especificamente, o Banco Central passou a monitorar o nível de crédito disponível, crescimento do produto, variações do ouro e das reservas em moedas estrangeiras, taxas de juros, taxa de câmbio e expectativas de inflação.

A partir de então, a África do Sul começou, de modo informal, a buscar níveis baixos de inflação (entre $1 \%$ a $5 \%$ a.a.) até o ano de 2000, quando o país adotou formalmente o regime de metas, e o alvo inflacionário foi fixado em um intervalo entre $3 \% \mathrm{e}$ $6 \%$. Ao longo da primeira década de 2000 , a taxa de inflação média anual foi de aproximadamente 5,9\%. Ressalta-se que, nesse período, a média de alguns anos foi relativamente elevada, especialmente em 2001 e 2008, reflexo dos choques externos e da forte aversão ao risco dos investidores internacionais, que provocou uma fuga de capitais, gerando forte volatilidade e depreciação da taxa de câmbio. Nesse mesmo período, a África do Sul experimentou um crescimento médio do PIB de 3,5\% a.a., o mais longo período de crescimento já registrado no país. 


\subsection{CHILE}

No início da década de 1980, o desempenho econômico do Chile expressa o próprio desempenho da América Latina como um todo. A partir de meados dos anos 1980, em um cenário internacional mais favorável, a economia chilena inicia um processo de recuperação, passando de um crescimento do PIB de 1,97\% em 1985 para 10,6\% em 1989. Na década de 1990 e na primeira década dos anos 2000, a performance do Chile manteve-se positiva, apresentando um crescimento médio do PIB de $6,4 \%$ e $4,2 \%$ ao ano, respectivamente. Em 2011, o produto chileno cresceu aproximadamente 6\%.

No que tange à inflação, ao longo da década de 1980, o Chile apresentou taxas médias de inflação de 21,4\%, sendo que o pico registrado foi em 1980 com uma inflação de 35\% a.a. Em 1989, o Banco Central do Chile tornou-se independente, tendo como objetivo principal zelar pela estabilidade da moeda e pelo normal funcionamento dos pagamentos internos e externos. Em virtude da crescente pressão inflacionária gerada pelas políticas expansionistas de 1988/1989 e pelo choque de preços do petróleo, originado da Guerra do Golfo, em 1990 o Chile adota (informalmente) o regime de metas de inflação, aliado a um regime de bandas cambiais e reformas para fortalecer o setor financeiro e manter o equilíbrio fiscal. O objetivo do banco central era sinalizar que implementaria políticas mais contracionistas no intuito de proteger a estabilidade monetária.

Desde então, nota-se uma expressiva melhora da inflação no país, sendo a média na década de 1990 próxima a 11,7\% a.a. Embora pareça ainda elevada, esta girava em torno de 26,6\% em 1990, tendo caído para 3,3\% em 1999, ano em que o país adotou formalmente o RMI, abandonando o regime de bandas cambiais. A partir daí a meta inflacionária do Chile tem sido de 3\%, podendo variar $1 \%$ para mais ou para menos. Na primeira década de 2000, a inflação média no país foi de 3,3\%, e, em 2011, fechou em 4,4\%.

\subsection{MÉXICO}

A história mexicana recente é marcada por duas graves crises econômicas. A primeira, provocada pela moratória de 1982, e a segunda, pela crise cambial de 1994/1995, as quais se estenderam por toda a América Latina.

Entre 1982-1989, enquanto o crescimento médio do PIB foi de 0,7\%, a economia mexicana experimentou uma inflação média à taxa de 79,5\%, tendo atingido 150\% em 1987. Nesse ano, as autoridades mexicanas decidiram implementar um agressivo programa de estabilização que incluía reformas fiscais e políticas de renda, tendo como instrumento principal a taxa de câmbio, utilizada como âncora nominal para romper a inércia inflacionária. A partir daí, a taxa de inflação seguiu uma trajetória declinante, 
atingindo $8 \%$ ao término de 1993 . No entanto, o período de desinflação foi acompanhado de acumulação de crescente deficit em conta corrente, financiado por capitais de curto prazo. O agravamento desse quadro culminou na crise financeira de 1994/1995. Foi nesse contexto, então, que o México implementou seu programa de estabilização. Já no ano seguinte, o país inicia um processo de recuperação econômica e queda do nível de preços, embora estes tenham se mantido em dois dígitos até 1999, ano que marca a adoção do RMI no país.

A taxa de inflação, que fechou a 12,3\% em 1999, caiu para $8,9 \%$ em 2000 . O período subsequente pode ser visto como o período em que a estabilização do nível de preços é, de fato, consolidada, em face de uma política monetária fortemente restritiva. A partir de 2002, a meta para a inflação no México foi fixada em 3\%, aceitando um intervalo de $1 \%$. Desde então, embora as metas não tenham sido sempre cumpridas, a média da inflação entre 2002 e 2011 foi de 4,3\%. Por outro lado, nesse mesmo período, o crescimento econômico foi de apenas $2,1 \%$ a.a., em média.

\subsection{COLÔMBIA}

Ao longo da década de 1980, embora a Colômbia tenha apresentado taxas modestas de crescimento do PIB, esse crescimento mostrou-se relativamente estável na faixa dos 3,3\% a.a., em média. Por outro lado, a inflação mostrou-se persistente no período, sendo sua média anual de 23,4\%. O comportamento dessas duas variáveis macroeconômicas manteve-se muito próximo ao da década de 1990, sendo a média de crescimento do produto ligeiramente inferior, $2,8 \%$, assim como a inflação, $22,1 \%$. Ressalta-se que, entre 1998 e 1999, a taxa de inflação recuou oito pontos percentuais, passando de 16,7\% para 9,2\%, resultado que coincide com a adoção do arranjo de metas inflacionárias em 1998.

Acompanhando a tendência mundial, a taxa de inflação caiu quase continuamente nos anos 2000. Nesse ínterim, o PIB cresceu à média de 4\% a.a. Em 2011, a inflação foi de $3,7 \%$, sendo o alvo inflacionário fixado em $3 \%$ (admitindo-se uma banda de $1 \%$ ), enquanto o produto cresceu $6 \%$.

Dada a boa performance recente, a Colômbia vem se destacando no panorama internacional, sendo incluída, em 2009, em um novo bloco econômico composto por países emergentes, denominado $\mathrm{CIVETS}^{2}$, os quais formam um grupo de economias

2 O termo CIVETS foi cunhado por Robert Ward, diretor de previsão global da empresa de consultoria britânica, a Economist Intelligence Unit (EIU), e compreende Colômbia, Indonésia, Vietnã, Egito, Turquia e África do Sul. 
que, apesar do risco, apresentam um grande potencial de crescimento e oportunidades atrativas de investimentos.

\subsection{COREIA DO SUL}

Apesar da recessão econômica global da década de 1980, a Coreia do Sul manteve uma taxa média de crescimento anual de 8,6\%, em virtude de uma base industrial com forte drive exportador voltado principalmente para os mercados da Ásia e América do Norte. Além disso, nos anos 1980, o comportamento da inflação na economia sul-coreana destoou bastante do observado na maioria dos países latino-americanos. A taxa média da inflação na década foi de 8,4\%. Na década seguinte, até 1998 a taxa média de inflação reduziu ligeiramente para $6,1 \%$, e o crescimento médio foi ainda elevado em 7,7\% a.a. Entretanto, a crise asiática de 1997/1998 impactou gravemente a economia sul-coreana. A taxa média de inflação e o crescimento do PIB, que haviam registrado $4,4 \%$ e 5,7\% em 1997, assinalaram 7,5\% e $-5,7 \%$ no ano seguinte, respectivamente.

Entretanto, ainda em 1998, imediatamente após a crise, os sul-coreanos mergulharam num processo de reinvenção. O país promoveu ampla reestruturação de sua política econômica e de seus conglomerados, os chaebols. No mesmo ano, buscando a estabilidade de preços, o país adota o regime de metas de inflação. Já no ano seguinte, a Coreia do Sul retoma o crescimento do PIB, atingindo a taxa de 10,7\%, e a inflação reduz-se a cerca de 1\%. No período subsequente, entre 1999 e 2011, a taxa de inflação da economia sul-coreana oscilou em torno de 3\%, que é justamente a meta atual do país, admitindo ainda uma banda de variação de $1 \%$.

\subsection{BRASIL}

No início do Plano Real, a taxa de câmbio foi utilizada como a principal âncora. Em um contexto de intensificação da abertura comercial, a taxa de câmbio sobrevalorizada, ao tornar mais competitivos os preços de produtos importados, serviu para impedir a elevação dos preços internos. No regime de câmbio adotado, havia um limite superior fixado para a taxa de câmbio, mas não havia um limite inferior fixado. Como resultado, a inflação média, que em 1994 foi de 2,075\%, caiu para 66\% no ano seguinte, sendo que ao final de 1995 foi de 22\%, e em fins de 1996, 9,5\%.

A queda da inflação proporcionou expansão do consumo e crescimento do PIB, e o governo, com medo do fantasma da inflação, elevou as reservas compulsórias, restringindo a política monetária e elevando a taxa de juros, que, por sua vez, provocou 
um grande influxo de capitais estrangeiros e a consequente valorização do câmbio. A demanda interna aquecida e câmbio valorizado formaram o cenário propício ao crescimento das importações, desequilíbrio na balança comercial e deficit na conta corrente. A elevada taxa de juros, por seu turno, contribuiu para atrair poupança externa e o financiamento do balanço de pagamentos. Nesse quadro de vulnerabilidade externa estoura a crise mexicana, que culminou em um ataque especulativo à moeda brasileira. Para conter a fuga de capitais, houve uma expressiva elevação da taxa de juros brasileira, com consequências negativas para o crescimento do PIB e da dívida pública.

Em 1997 e 1998, as crises do leste asiático e russa provocaram novo ambiente de aversão ao risco na economia mundial, que resultou em outro ataque especulativo contra o real. No entanto, após a crise russa, a elevação da taxa de juros não foi suficiente para conter a fuga de capitais. Pressionado e não conseguindo sustentar o câmbio, em janeiro de 1999 o Brasil deixa o câmbio flutuar. Como esperado, houve uma intensa depreciação do real e o Banco Central do Brasil (BCB), novamente, no intuito de evitar uma elevação da inflação, recorreu ao aumento da taxa de juros. Procurando reestabelecer a estabilidade econômica, em março do mesmo ano, o BCB, sob nova direção, adota informalmente o RMI como "solução" e única saída para uma política monetária baseada no câmbio fixo ${ }^{3}$, arranjo que se formaliza em junho do mesmo ano. O custo da estabilização foi um crescimento econômico inexpressivo de $0,03 \%$ em 1999.

Na última década, a estabilização dos preços pareceu finalmente se consolidar no Brasil, sendo que as metas não foram cumpridas apenas entre 2001-2003, período que envolveu choques inesperados, como desaquecimento da economia dos EUA com a queda das bolsas de valores e os atentados terroristas, a elevação do preço internacional do petróleo, o contágio da crise argentina e, internamente, a crise energética de 2001 e o "efeito Lula" em 2002-2003. Esses fatores deterioraram a percepção de risco em relação ao Brasil e pressionaram fortemente a taxa de câmbio, cujo pass-through exerceu forte impacto nos índices de preços. Desde então, as metas têm sido cumpridas ano a ano, sendo que atualmente o alvo inflacionário é de $4,5 \%$, admitindo-se uma banda de variação de $2 \%$.

Em termos de crescimento econômico, este não conseguiu fugir ao padrão stop and go, explicado, em boa parte, pela manutenção das taxas de juros em patamares muito elevados. Além disso, no Brasil, em virtude de sua elevada vulnerabilidade externa estrutural, fica evidente a existência de fear of floating, com a autoridade mone-

3 Ver Modenesi (2005). 
tária reagindo constantemente às variações na taxa de câmbio. Dessa forma, o principal instrumento de política monetária, a taxa de juros, acaba sendo utilizado tanto para controlar a inflação como para manter o balanço de pagamento em equilíbrio.

\section{CARACTERÍSTICAS DO RMI NOS PAÍSES SELECIONADOS}

As características do RMI no mundo têm grande variabilidade dependendo do país analisado. Essa variação diz respeito ao framework institucional do RMI, os índices de preços utilizados, o horizonte temporal estipulado pelo banco central (BC) para convergência da meta, os instrumentos monetários utilizados pelo $\mathrm{BC}$, além dos princípios de prestação de contas (accountability) e transparência inerentes a esse regime de política monetária.

Como enfatizam Rocha e Oreiro (2008), a formatação institucional de cada RMI é crucial para garantir a obtenção das metas e a construção da credibilidade. No momento em que o regime é utilizado, os policy-makers têm vasta possibilidade de escolha no sentido de estabelecer a forma institucional pela qual o regime vai operar, isto é, se amparado no núcleo ou no índice cheio de inflação, se estabelecendo um valor numérico de convergência para a taxa de inflação ou bandas de intervalo de amplitudes diversas, se anunciando um horizonte temporal de um ano ou um prazo maior pelo qual se espera que a inflação tenha convergência à meta estabelecida etc. Cada uma dessas escolhas pode dar ao regime uma roupagem institucional específica: ele pode ser mais "rígido", no sentido de que é estruturado com forte ênfase no sucesso das metas estabelecidas, sem grande preocupação com os custos de operacionalização dessa convergência; ou pode ser mais "flexível", na medida em que leva em consideração os custos e o horizonte temporal exigido para o cumprimento das metas.

No que diz respeito à gestão do regime de metas em economias emergentes, Farhi (2007) ressalta que as reações da autoridade monetária aos choques exógenos constituem seu traço mais marcante, e é em função dessa reação que se pode distinguir a prática flexível do regime de metas, que minimiza seu impacto no produto e no emprego, da prática mais rígida, que no afã de obter uma inflação baixa não leva em consideração esse impacto. Assim, no caso dos países emergentes, seja pela ausência de precondições institucionais, técnicas e econômicas ${ }^{4}$, seja pela não consideração do

\footnotetext{
As precondições apontadas por Farhi (2007) remetem ao trabalho de Eichengreen et al. (1999), e pertencem a quatro amplas categorias: i) independência institucional, em que o banco central deve ter plena autonomia legal e estar livre de pressões fiscais e políticas que criem conflitos com a meta de inflação; ii)
} 
histórico inflacionário específico de cada país e da dimensão hierárquica de moedas no plano internacional, a adoção de arranjos muito rígidos tende a apresentar custos sociais elevados na busca de convergência das taxas de inflação para a meta estipulada pelo $\mathrm{BC}$, uma vez que, quanto maior a rigidez com que o regime é implantado, maior será a volatilidade das taxas de juros e do produto. Nesse particular, a autora ressalta a alta volatilidade e o elevado pass-through da taxa de câmbio nessas economias, tornando a política monetária e, portanto, a taxa de juros, refém do regime cambial adotado. Portanto, um regime flexível seria mais adequado a esses países. No entanto, o que se verifica é que no início da aplicação desse tipo de política monetária, maior ênfase é dada à inflação, como uma forma de adquirir credibilidade.

Também na defesa por regimes mais flexíveis, Squeff, Oreiro e Paula (2009) argumentam que é possível definir um intervalo de flexibilidade institucional para o RMI, no qual um alto grau de flexibilidade é associado com uma política monetária mais expansionista, em que os aumentos das taxas de juros são menores e menos frequentes. Esse comportamento das taxas de juros poderia contribuir para uma trajetória menos volátil do crescimento do produto e dos gastos com investimento, aspectos que são frequentemente negligenciados na literatura sobre o RMI. Ademais, os autores defendem que um regime de caráter mais flexível pode (e deve) ser adotado pelos países emergentes, mesmo aqueles com histórico recente de inflação elevada. Desse modo, o grau de flexibilidade deve ser aquele que permita aos bancos centrais perseguir seu duplo mandato - preços estáveis e o máximo de emprego com taxa de juros moderadas - por meio da utilização de uma meta numérica de inflação mais elevada, núcleo da inflação, maior período de convergência etc. Sendo insuficientes, ferramentas complementares de política econômica podem ser usadas. Por exemplo, diante dos problemas associados ao excessivo afluxo de capitais sobre a taxa de câmbio, controles sobre a entrada de capitais podem ser adotados; adicionalmente, "controles prudenciais de crédito" podem ser empregados para controlar a demanda agregada quando a economia estiver superaquecida, visando evitar os efeitos nocivos do aumento da taxa de juros sobre as variáveis reais.

infraestrutura técnica bem desenvolvida, i.e., o banco central deve ter a capacidade de prever a inflação, de elaborar modelos e os dados necessários para implementá-los; iii) estrutura econômica, em que os preços devem estar totalmente desregulados, a economia não pode ser excessivamente sensível aos preços das commodities e à taxa de câmbio e a dolarização deve ser mínima; iv) sistema financeiro sadio, i.e., são necessários um sistema bancário sólido e um mercado de capitais desenvolvido para minimizar os potenciais conflitos entre a política monetária e os objetivos de estabilização financeira e garantir a eficácia dos mecanismos de transmissão da política monetária. 
É em sentido semelhante que, para alguns dos críticos do RMI, admitindo-se que a hipótese das múltiplas causas da inflação seja válida, isto é, considerando além da inflação de demanda a possibilidade de pressões do lado da oferta - oriundos de aumentos exógenos nos salários, do grau de concentração nos mercados, de choques exógenos de oferta, de impostos e de retornos decrescentes de escala - e que o governo seja bem-sucedido na identificação das origens, então políticas discricionárias com a utilização de instrumentos alternativos ou paralelos à taxa nominal de juros podem ser mais eficazes no combate à inflação. Nesse caso, a taxa de juros nominal poderia ser menor, reduzindo os custos sociais atrelados à gestão de um regime de metas (MODENESI, 2005).

Em suma, ao decidir adotar o regime de metas de inflação como sua política monetária, cada país determina uma série de parâmetros que configurarão seu formato específico, dentro de um modelo mais genérico. Esses distintos formatos adotados, se mais ou menos rígidos (flexíveis), têm fortes impactos tanto na gestão do regime de metas, já que esta deve cumprir as imposições neles contidos, quanto, consequentemente, no seu desempenho macroeconômico. Essa diversidade de arranjos pode ser verificada na Tabela 1, que mostra resumidamente as particularidades do RMI em Brasil, Chile, Colômbia, México, África do Sul e Coreia do Sul.

O primeiro ponto que se quer destacar sobre a institucionalidade do RMI diz respeito à sua independência. Na literatura convencional ${ }^{5}$, o principal aspecto é a distinção da independência formal, ou não, da autoridade monetária, de forma a impedir o chamado "viés inflacionário", oriundo de pressões políticas. Dos seis países analisados, apenas no Chile e no México observa-se a independência formal da autoridade monetária. Nos demais, incluindo o Brasil, não há uma independência institucional, apenas independência de instrumentos, ou seja, esses bancos centrais são independentes para a política monetária e nada mais. Entretanto, há cinco aspectos importantes a serem considerados, no que concerne a flexibilização do regime de metas de inflação.

O primeiro refere-se à accountability da autoridade monetária, isto é, qual a relação que BC, governo e sociedade têm na condução da política monetária. Averigua-se que, nos seis países em questão, a meta é determinada pelo governo, tendo ocasionalmente a participação do BC (como é caso da África do Sul e Coreia do Sul). O Brasil é a exceção, uma vez que quem define a meta de inflação é o Conselho Monetário Nacional (CMN) composto pelo presidente do BC e pelos ministros da Fazenda e do Planejamento. No Chile e no México, com ambos usufruindo de independência formal, os BC devem prestar esclarecimentos periodicamente para o Congresso de seus países. Já nos demais, o $\mathrm{BC}$ deve explicar-se apenas em caso de não cumprimento da meta fixada.

\footnotetext{
Ver Rogoff (1985); Cukierman (1992, 1994); Goodhart (1994); Walsh (1995); Alesina e Gatti (1995); Alesina e Summers (1993).
} 


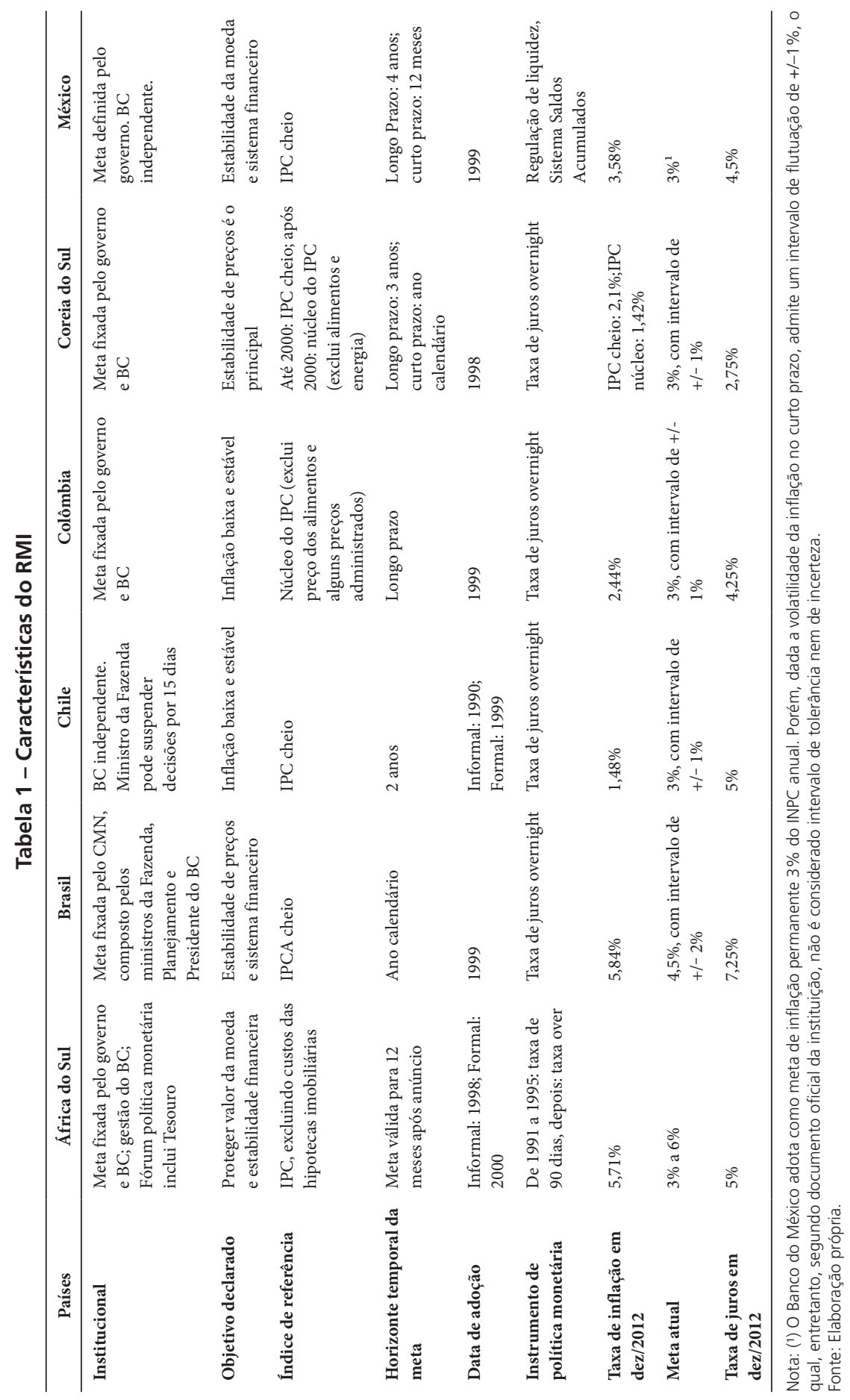


O segundo aspecto institucional refere-se à composição do comitê incumbido de tomar as decisões de política monetária. No Chile, as decisões são feitas pelos membros da diretoria do BC e a presença do ministro da Fazenda nas reuniões é facultativa, sendo que o ministro tem direito à palavra, mas não tem direito a voto. $\mathrm{Na}$ África do Sul, as decisões são tomadas pelo Monetary Policy Commitee (MPC), o qual é composto por nove membros, a saber: o presidente do BC, três vice-presidentes e cinco diretores. No Brasil, compõem o comitê todos os membros da diretoria da autoridade monetária, incluindo das áreas administrativas. Nos demais países, o comitê é composto por membros tecnicamente qualificados da diretoria do BC.

Outro ponto relevante são os objetivos explícitos dos BC. Nesse ponto, os bancos centrais dos países selecionados apresentam conformidade na definição do objetivo: garantir um sistema financeiro sólido e uma inflação baixa e estável. Além disso, as características dos arranjos adotados na particularização da meta de inflação também são uniformes entre os países selecionados. Cabe salientar que a Coreia do Sul é o único país da amostra que utiliza um índice de inflação núcleo (excluindo os preços de energia e alimentos, que são preços sujeitos a choques exógenos de oferta). Contudo, o uso do core inflation foi adotado apenas em 2000, sendo que de 1998 até essa data os sul-coreanos utilizaram o índice cheio. O índice da África do Sul, embora não se caracterize como um índice core, expurga de seu cálculo o custo das hipotecas imobiliárias, em virtude desse item sofrer influência direta da política monetária. Os demais países, assim como o Brasil, utilizam índices de preços ao consumidor cheio.

O terceiro ponto importante da análise do RMI é o horizonte temporal para convergência da inflação à meta estipulada. O Brasil admite o ano calendário (isto é, um ano de horizonte temporal) para o cumprimento da meta, sendo o objetivo da política monetária definido com 18 meses de antecedência. Mesmo assim, entre os países analisados, o Brasil é o país que tem o horizonte temporal mais curto de objetivo de meta. O país que mais se aproxima do Brasil é a África do Sul, que estipula a meta a ser alcançada nos 12 meses seguintes ao anúncio. O Chile e a Colômbia adotam um horizonte um pouco mais longo, de dois anos, e sem metas intermediárias. Coreia do Sul e México apresentam um horizonte de longo prazo (três anos), além de metas intermediárias de curto prazo. Um aspecto interessante é que países com horizonte temporal mais alongado têm mais vantagem em relação aos países que têm um horizonte mais curto, como um ano. Isso ocorre porque, com prazos maiores, os agentes formam expectativas de longo prazo, o que propicia maior flexibilidade para a política monetária, permitindo atenuar choques de oferta exógenos, além de proporcionar um tempo maior para a efetiva transmissão da política.

O quarto ponto importante a se analisar é a meta propriamente dita de inflação adotada por cada país. Analisando os países das metas mais "estreitas" para as mais "amplas" temos o México com uma meta de 3\% de inflação ao ano, sem nenhum inter- 
valo de tolerância formal. Entretanto, há um consenso de que o Banco Central do México adote informalmente um intervalo de $\pm 1 \%$, conforme alguns relatórios disponíveis no site do BC. Em seguida têm-se Chile, Colômbia e Coreia do Sul, que perseguem uma meta de inflação de $3 \%$ a.a. agora com um intervalo de tolerância formal de $\pm 1 \%$. Isso significa que a inflação nesses países, incluindo até o caso informal do México, pode variar entre $2 \%$ e $4 \%$ ao ano. Depois vem o caso da África do Sul, que não tem uma meta propriamente definida em um valor, mas sim dentro de um intervalo, que varia de $3 \%$ a $6 \%$ ao ano. Por último, o Brasil, que tem a meta de $4,5 \%$ ao ano, podendo variar \pm $2 \%$ a inflação. Isso significa que a inflação brasileira pode ficar entre 2,5\% e 6,5\% ao ano, demonstrando, assim, a meta com maior amplitude entre todos os países analisados.

O último ponto a se analisar refere-se aos instrumentos usados pela política monetária nesses países. Nesse ponto, pode-se dizer que há maior uniformidade entre os países analisados. África do Sul, Brasil, Chile, Colômbia e Coreia utilizam as taxas de juros de curtíssimo prazo (overnight) como instrumento. O México é o único país a usar um mecanismo diferente, uma vez que se vale de um sistema baseado em regulação da liquidez e os saldos acumulados, isto é, na essência, o sistema mexicano pratica o controle da base monetária.

Apresentadas as características institucionais do RMI de cada país, se faz necessário analisar os dados de inflação e taxa de juros como uma forma comparativa de eficácia da política monetária nestes países. Para o ano de 2012, a meta de inflação não foi alcançada pelo Chile e pela Coreia do Sul, uma vez que seus resultados ficaram abaixo das metas estipuladas. A inflação chilena foi de 1,48\% a.a., enquanto que a coreana foi de 1,42\% a.a., abaixo das metas e dos desvios adotados por estes países. No restante da amostra, todos os países lograram êxito em manter a inflação dentro das metas estipuladas. África do Sul, Brasil e México tiveram suas inflações acima da meta, mas dentro do intervalo de tolerância. A Colômbia teve sua inflação abaixo da meta, mas também dentro do intervalo de intolerância.

No que concerne à taxa de juros, percebe-se uma grande discrepância entre o Brasil e o resto dos países. Quando se compara o Brasil a países com mesma renda per capita, como Chile e México, a taxa de juros brasileira chega a ser muito superior à praticada nesses países. Enquanto que o intervalo de taxa de juros dos outros países analisados se situa entre $2,75 \%$ e $5 \%$, o Brasil destoa da amostra, com uma taxa de juros de $7,25 \%$ a.a. Sem a pretensão de esgotar o debate sobre o tema, cabe mencionar Bresser-Pereira e Gomes (2009), que citam alguns motivos que justificariam a tão elevada taxa de juros no Brasil:

Essencialmente porque a armadilha juros/câmbio impede que ela seja reduzida. Uma causa secundária é o alto nível de gastos públicos comparado ao patamar de 
renda per capita do país. Em terceiro lugar, porque as autoridades monetárias aumentam a taxa Selic, tentando (sem sucesso) alongar o vencimento da dívida (para construir um mercado de crédito doméstico de longo prazo). Em quarto lugar, e esta provavelmente seja a razão principal, porque a Selic indexa a maior parte da dívida pública. [...] Em quinto lugar, a taxa Selic é alta porque o Banco Central (do Brasil) a usa como ferramenta para resolver outros tipos de problemas, além de controlar a inflação. Por exemplo, ela é usada para: a) atrair capital estrangeiro; b) reduzir o déficit em conta corrente quanto este cresce continuamente; c) aumentar a poupança pública. O sexto ponto está relacionado a uma causa de economia política. Por este prisma, a taxa Selic é alta porque, desde o final da década de 1980, o Banco Central tem sido "capturado" pelos rentistas, que sempre ganham com as altas taxas de juros, pelo setor financeiro, que vive de comissões/bônus provenientes de rentistas, e pelas multinacionais, que aumentam suas remessas de lucros com um real sobrevalorizado. O sétimo ponto está relacionado a uma causa de hegemonia ideológica: Washington, e especificamente o FMI, apoia fortemente a política monetária brasileira em vigor - o que não é de surpreender: a ortodoxia convencional que esse organismo e os mercados financeiros internacionais usam para pressionar os países em desenvolvimento de renda média é essencialmente uma ferramenta para neutralizar seus crescimentos ${ }^{6}$. (BRESSER-PEREIRA e GOMES, 2009, p. 37)

O primeiro motivo citado pelos autores ocorre quando a autoridade monetária tenta reduzir a taxa de juros, tendo como reação uma depreciação cambial, que pressiona a inflação interna via produtos importados. O segundo ponto, de que o governo mantém os gastos públicos elevados para o atual nível renda per capita, relaciona os elevados gastos que o governo central realiza comparados ao padrão de renda per capita brasileiro, que ainda é muito baixo. O terceiro motivo relaciona as altas taxas de juros com a tentativa da autoridade monetária de alongar o vencimento da dívida, isto é, quando se tenta alongar a curva de rendimentos (yield curve) com a intenção de criar um mercado doméstico de crédito. Contudo, essa tentativa de alongamento da dívida não obtém o resultado desejado, mantendo a curva de rendimentos com um horizonte temporal curto. O quarto argumento levantado pelos autores é a existência de títulos públicos que são remunerados pela Selic. Segundo os autores, ter uma dívida indexada à principal ferramenta de transmissão da política monetária - a taxa de juros

6 Bresser-Pereira (2006). 
Selic - gera instabilidades econômicas de curto prazo, mesmo que a proporção dessa dívida tenha caído nos últimos anos.

No quinto ponto, os autores mostram que a autoridade monetária usa a taxa Selic como ferramenta para resolver outros problemas, como atrair capital externo, reduzir o deficit em conta corrente e aumentar a poupança pública. Mais especificamente, elevações das taxas de juros são utilizadas para gerenciar o saldo da conta capital e financeira de modo a manter o balanço de pagamentos equilibrado, tendo em vista os recorrentes deficit nas transações correntes. Além disso, a contração da demanda agregada contribui para a redução das importações, melhorando o saldo da conta corrente. Finalmente, o manejo da taxa de juros atua no sentido de aumentar a atratividade dos títulos públicos, ampliando a poupança pública. O problema dessa fórmula é que o capital externo atraído pelas altas taxas de juros é muito volátil, podendo sair em qualquer momento de desconfiança ou mesmo de resultados ruins na economia brasileira, impondo a necessidade de novos aumentos de juros para segurar o capital e atrair ainda mais recursos. Contudo, embora a captação de recursos se dê em grande parte por este mecanismo, as despesas com o pagamento de juros da dívida também se elevam, gerando maior necessidade futura de captações, i.e., maiores elevações das taxas de juros, para honrar seus compromissos financeiros.

O sexto ponto levantado trata-se da tese de captura do Banco Central, segundo a qual este seria capturado pelos rentistas, de modo que as decisões do BC atenderiam aos seus interesses. Isso pode se traduzir, por exemplo, no cargo de presidente do Banco Central. Os dois presidentes anteriores ao atual, Alexandre Tombini, vieram do mercado financeiro, o que poderia corroborar a tese de captura do Banco Central pelos rentistas, até o ano de 2011. Essa tese de captura do Banco Central tem sido tema de debate nos últimos anos, principalmente depois da crise financeira internacional de 2008. Segundo Boyer e Ponce (2010) e Canova (2014), há indícios de que muitos bancos centrais formalmente "independentes" ao redor do mundo foram capturados pelo setor financeiro em benefício deste e em detrimento do resto da sociedade. Embora não se possa afirmar categoricamente que este é o caso do Brasil, a tese de captura abre espaço para investigações nesse sentido.

O sétimo e último ponto está diretamente relacionado ao anterior. Na concepção dos autores, o Consenso de Washington, por meio do Fundo Monetário Internacional (FMI), apoia fortemente essa política monetária de altas taxas de juros, para que as economias de renda média tenham seus crescimentos neutralizados. Essa teoria tem seu embrião nos argumentos de Chang (2006), segundo o qual os países desenvolvidos "chutam a escada" para que os países em desenvolvimento não se desenvolvam. 
Feitas as devidas considerações acerca das características do RMI nos países selecionados, a próxima seção visa analisar empiricamente a eficácia da política monetária nesses países no que diz respeito ao controle da inflação.

\section{ANÁLISE EMPÍRICA}

O objetivo desta seção é analisar, por meio do modelo de Vetores de Correção de Erros (VEC), a consistência da política monetária nos países analisados.

\subsection{ANÁLISE DAS SÉRIES UTILIZADAS}

A implementação formal do RMI nos países selecionados ocorreu entre 1998 e 2000, constituindo-se assim uma mudança na condução da política monetária nessas economias. No entanto, para uma comparação adequada dos dados, optou-se por padronizar o horizonte de análise para esses países, com início em janeiro de 2000 até junho de 2012. Ao todo são 152 observações, o que confere uma boa confiabilidade aos resultados obtidos ${ }^{7}$. Devido à diferença de coleta de dados relativa a cada BC, buscou-se manter um padrão mínimo, com o intuito de se obter resultados compatíveis com a teoria existente. Em todos eles, as variáveis usadas são: Juros (a taxa de juros efetiva de cada país, anualizada); IPC (taxa de variação mensal dos índices de preços de cada país); Ind (índice industrial de produção física, com ajuste sazonal) e Câmbio (taxa de câmbio nominal, média mensal). A ordem escolhida para o modelo VEC é Juros, IPC, Ind e Câmbio, para todos os países. A taxa de juros foi escolhida como a variável mais exógena, já que é o instrumento de política monetária. A taxa de câmbio foi escolhida como a mais variável endógena, uma vez que, através do canal de expectativas, esta pode ser afetada simultaneamente por todas as outras variáveis. Por fim, com base na literatura econômica e reforçado pelos testes de causalidade de Granger (Tabela 5), o índice de preços precede a proxy de atividade econômica (Ind).

Esses dados estão disponíveis nos respectivos BC de cada país e são os dados oficiais utilizados no âmbito da política monetária. Todas as variáveis são usadas em escala logarítmica. Assim, o termo lncambio, por exemplo, refere-se ao logaritmo natural da variável Câmbio.

\footnotetext{
Wooldridge (2002) cita que uma amostra confiável é aquela com mais de 60 observações. No caso acima, há mais de 150, o que dá uma maior credibilidade aos resultados obtidos. Além disso, uma regressão econométrica é dita confiável quando se tem um número de observações maior do que de variáveis. Nos modelos estimados, essa regra prevalece.
} 
Tabela 2 - Resultados dos testes de Dickey-Fuller Aumentado (ADF); Dickey-Fuller GLS (DF-GLS); Phillips-Perron (PP); Kwiatkowski-Phillips-Schmidt-Shin (KPSS) e a Decisão

\begin{tabular}{|c|c|c|c|c|c|}
\hline \multicolumn{6}{|c|}{ África do Sul } \\
\hline Variável & ADF & ADF-GLS & PP & KPSS & Decisão \\
\hline lncambio $^{2}$ & $\mathrm{I}(1)^{* * *}$ & $\mathrm{I}(1)^{* * *}$ & $\mathrm{I}(1)^{* * *}$ & $\mathrm{I}(0)$ & $\mathrm{I}(1)$ \\
\hline $\operatorname{lnipc} c^{1}$ & $\mathrm{I}(1)^{* * *}$ & $I(1)^{* * *}$ & $\mathrm{I}(1)^{* * *}$ & $\mathrm{I}(1)$ & $\mathrm{I}(1)$ \\
\hline $\operatorname{lnjuros}^{1}$ & $(0)^{* *}$ & $\mathrm{I}(1)^{\star *}$ & $I(2)^{* * *}$ & $\mathrm{I}(0)$ & $\mathrm{I}(\mathbf{0})$ \\
\hline $\operatorname{lnind}^{1}$ & $I(2)^{\star * *}$ & $\mathrm{I}(1)^{*}$ & $\mathrm{I}(1)^{* * *}$ & $\mathrm{I}(1)$ & $\mathrm{I}(1)$ \\
\hline \multicolumn{6}{|l|}{ Brasil } \\
\hline Variável & $\mathrm{ADF}$ & ADF-GLS & $\mathrm{PP}$ & KPSS & Decisão \\
\hline $\operatorname{lncambio}^{1}$ & $\mathrm{I}(1)^{\star * *}$ & $\mathrm{I}(1)^{\star * *}$ & $\mathrm{I}(1)^{\star * *}$ & $\mathrm{I}(1)$ & $\mathrm{I}(1)$ \\
\hline $\operatorname{lnjuros}^{1}$ & $\mathrm{I}(0)^{\star *}$ & $\mathrm{I}(0)^{\star *}$ & $\mathrm{I}(1)^{* *}$ & $\mathrm{I}(1)$ & $\mathrm{I}(1)$ \\
\hline $\operatorname{lnind}^{1}$ & $\mathrm{I}(1)^{* * *}$ & $\mathrm{I}(1)^{* * *}$ & $\mathrm{I}(1)^{* * *}$ & $\mathrm{I}(1)$ & $\mathrm{I}(1)$ \\
\hline$\underline{\operatorname{lnipc} c^{1}}$ & $\mathrm{I}(1)^{* * *}$ & $\mathrm{I}(0)^{\star *}$ & $\mathrm{I}(1)^{* * *}$ & $\mathrm{I}(1)$ & $\mathrm{I}(\mathbf{1})$ \\
\hline \multicolumn{6}{|l|}{ Chile } \\
\hline Variável & $\mathrm{ADF}$ & ADF-GLS & $\mathrm{PP}$ & KPSS & Decisão \\
\hline $\operatorname{lncambio}^{1}$ & $\mathrm{I}(0)^{\star}$ & $\mathrm{I}(1)^{\star * *}$ & $\mathrm{I}(1)^{\star * *}$ & $\mathrm{I}(1)$ & $\mathrm{I}(1)$ \\
\hline $\operatorname{lnipc} c^{1}$ & $\mathrm{I}(1)^{* * *}$ & $\mathrm{I}(1)^{* * *}$ & $\mathrm{I}(1)^{* * *}$ & $\mathrm{I}(1)$ & $\mathrm{I}(1)$ \\
\hline $\operatorname{lnjuros}^{1}$ & $\mathrm{I}(1)^{* * *}$ & $\mathrm{I}(1)^{* * *}$ & $\mathrm{I}(1)^{* * *}$ & $\mathrm{I}(0)$ & $\mathrm{I}(1)$ \\
\hline $\operatorname{lnind}^{1}$ & $\mathrm{I}(1)^{* * *}$ & $\mathrm{I}(1)^{* * *}$ & $\mathrm{I}(1)^{* * *}$ & $\mathrm{I}(1)$ & $\mathrm{I}(\mathbf{1})$ \\
\hline \multicolumn{6}{|l|}{ Colômbia } \\
\hline Variável & $\mathrm{ADF}$ & ADF-GLS & $\mathrm{PP}$ & KPSS & Decisão \\
\hline $\operatorname{lncambio}^{1}$ & $\mathrm{I}(1)^{\star * *}$ & $\mathrm{I}(1)^{\star * *}$ & $\mathrm{I}(1)^{* * *}$ & $\mathrm{I}(1)$ & $\mathrm{I}(1)$ \\
\hline $\operatorname{lnipc} c^{1}$ & $\mathrm{I}(1)^{* * *}$ & - & $\mathrm{I}(1)^{* * *}$ & $\mathrm{I}(1)$ & $\mathrm{I}(1)$ \\
\hline $\operatorname{lnjuros}^{1}$ & $\mathrm{I}(1)^{*}$ & $\mathrm{I}(1)^{*}$ & $\mathrm{I}(2)^{* * *}$ & $\mathrm{I}(1)$ & $\mathrm{I}(1)$ \\
\hline $\operatorname{lnind}^{1}$ & $\mathrm{I}(0)^{*}$ & $\mathrm{I}(0)^{* *}$ & $\mathrm{I}(1)^{* * *}$ & $\mathrm{I}(1)$ & $\mathrm{I}(1)$ \\
\hline \multicolumn{6}{|l|}{ Coreia } \\
\hline Variável & $\mathrm{ADF}$ & ADF-GLS & PP & KPSS & Decisão \\
\hline $\operatorname{lncambio}^{1}$ & $\mathrm{I}(1)^{* * *}$ & $\mathrm{I}(1)^{* * *}$ & $\mathrm{I}(1)^{* * *}$ & $\mathrm{I}(1)$ & $\mathrm{I}(1)$ \\
\hline $\operatorname{lnjuros}^{2}$ & $\mathrm{I}(1)^{* * *}$ & $\mathrm{I}(0)^{\star *}$ & $\mathrm{I}(1)^{* * *}$ & $\mathrm{I}(1)$ & $\mathrm{I}(1)$ \\
\hline $\operatorname{lnind}^{1}$ & $\mathrm{I}(0)^{\star * *}$ & $\mathrm{I}(0)^{\star * *}$ & $\mathrm{I}(1)^{\star *}$ & $\mathrm{I}(0)$ & $\mathrm{I}(0)$ \\
\hline$\underline{\operatorname{lnipc} c^{1}}$ & $\mathrm{I}(1)^{* * *}$ & $\mathrm{I}(1)^{\star * *}$ & $\mathrm{I}(1)^{* * *}$ & $\mathrm{I}(1)$ & $\mathrm{I}(1)$ \\
\hline \multicolumn{6}{|l|}{ México } \\
\hline Variável & $\mathrm{ADF}$ & ADF-GLS & PP & KPSS & Decisão \\
\hline $\operatorname{lncambio}^{1}$ & $\mathrm{I}(0)^{\star *}$ & $\mathrm{I}(0)^{\star * *}$ & $\mathrm{I}(1)^{\star * *}$ & $\mathrm{I}(0)$ & $\mathrm{I}(0)$ \\
\hline $\operatorname{lnipc} c^{1}$ & $\mathrm{I}(1)^{*}$ & - & $\mathrm{I}(0)^{* *}$ & $\mathrm{I}(1)$ & $\mathrm{I}(1)$ \\
\hline $\operatorname{lnjuros}^{1}$ & $\mathrm{I}(1)^{* * *}$ & $\mathrm{I}(1)^{* * *}$ & $\mathrm{I}(1)^{* * *}$ & $\mathrm{I}(1)$ & $\mathrm{I}(1)$ \\
\hline $\operatorname{lnind}^{1}$ & $\mathrm{I}(1)^{\star * *}$ & $\mathrm{I}(1)^{* * *}$ & $\mathrm{I}(1)^{* * *}$ & $\mathrm{I}(0)$ & $\mathrm{I}(1)$ \\
\hline
\end{tabular}

Notas: $\left({ }^{1}\right)$ Tendência e Intercepto, $\left({ }^{2}\right)$ Intercepto. ( - ) Sem resultados significativos. $\left({ }^{*}\right)$ Significativo a $10 \% .\left({ }^{*}\right)$ Significativo a $5 \%$. $\left(^{* * *}\right)$ Significativo a $1 \%$.

Fonte: Elaboração própria.

Com o intuito de se avaliar se as variáveis seguem um padrão estocástico estacionário, foram realizados quatro testes de raiz unitária ${ }^{8}$. A Tabela 2 mostra os resultados dos testes de Dickey-Fuller Aumentado; Dickey-Fuller GLS (Elliott, Rothenberg e

\footnotetext{
8 Confira Bueno (2011, Cap. 4); Greene (2012, Cap. 21).
} 
Stock, 1996); Phillips-Perron (1987); Kwiatkowski-Phillips-Schmidt-Shin (1992), explicitando a ordem de integração estatisticamente significativa de cada variável. As hipóteses nulas dos testes são de que as séries são não estacionárias, com exceção do teste de Kwiatkowski-Phillips-Schmidt-Shin (KPSS), cuja hipótese nula é a de que as séries são estacionárias, isto é, o oposto dos outros testes. Ao lado direito de cada país encontra-se a ordem de decisão de integração conforme os resultados dos testes. Ademais, os asteriscos mostram o nível de significância de cada teste para a variável em questão. Percebe-se que a grande maioria das variáveis utilizadas é integrada de ordem um, I(1). Apenas três variáveis são integradas de ordem zero, I(0): lnjuros da África do Sul; lnipc da Coreia do Sul; e lncambio do México. A adição de variáveis com ordens de integração diferentes, nos casos citados, será justificada na seção seguinte, nos testes de cointegração. No caso brasileiro, todas as variáveis são integradas de ordem um, I(1), corroborando os resultados obtidos em outros trabalhos, de que as séries não são estacionárias em nível9 ${ }^{9}$

\subsection{MODELO VEC: ESTIMAÇÃO E RESULTADOS}

Como verificado acima, há evidências de que quase todas as séries utilizadas são I(1). Dessa forma, realizou-se o teste de cointegração de Johansen ${ }^{10}$ com o objetivo de averiguar se uma combinação linear dessas variáveis é estacionária, indicando assim que existe uma relação de longo prazo entre estas. Nos casos da África do Sul, Coreia do Sul e México, ao chegar num processo de cointegração entre variáveis estacionárias, a adição de uma variável não estacionária não causa alterações significativas na robustez estatística da regressão, segundo Campbell e Perron (1991). Na Tabela 2 estão expostos os resultados do teste de cointegração para todos os países analisados. A hipótese nula é de que não há relação de cointegração entre as variáveis.

Como resultado, todos os países rejeitam a hipótese nula em um nível de 5\% de significância, tanto pela estatística do traço quanto pelo do máximo autovalor. Portanto, há forte evidência de que existe pelo menos um vetor de cointegração para cada país, e que isso representa a relação de longo prazo entre as variáveis. Dessa forma, evita-se o problema de regressão espúria, que pode ocorrer em regressões de séries temporais.

\footnotetext{
9 Ver Araújo e Modenesi (2008, 2011) e Parreiras (2007).

10 Ver Engle e Granger (1987); Johansen (1988); Johansen e Juselius (1990).
} 
Tabela 3 - Teste de Johansen para todos os países

\begin{tabular}{lccccccc}
\hline \multirow{2}{*}{ País } & $\begin{array}{c}\mathbf{N}^{\circ} \text { de cointe- } \\
\text { grações }\end{array}$ & \multicolumn{3}{c}{ Estat. do traço } & \multicolumn{3}{c}{ Estat. do máximo valor } \\
\cline { 2 - 8 } & & Observado & Valor crítico 5\% & P-valor & Observado & Valor crítico 5\% & P-valor \\
\hline \multirow{2}{*}{ África do Sul } & $\mathrm{R}=0$ & $\mathbf{5 9 , 9 2 8 2 6}$ & $\mathbf{5 4 , 0 7 9 0 4}$ & $\mathbf{0 , 0 1 3 7}$ & $\mathbf{3 2 , 3 4 7 6 5}$ & $\mathbf{2 8 , 5 8 8 0 8}$ & $\mathbf{0 , 0 1 5 7}$ \\
& $\mathrm{R} \leq 1$ & 27,58061 & 35,19275 & 0,2605 & 17,97694 & 22,29962 & 0,1803 \\
\hline \multirow{2}{*}{ Brasil } & $\mathrm{R}=0$ & $\mathbf{7 0 , 5 2 0 5 1}$ & $\mathbf{6 3 , 8 7 6 1}$ & $\mathbf{0 , 0 1 2 4}$ & $\mathbf{3 5 , 4 4 3 2 6}$ & $\mathbf{3 2 , 1 1 8 3 2}$ & $\mathbf{0 , 0 1 8 8}$ \\
& $\mathrm{R} \leq 1$ & 35,07726 & 42,91525 & 0,2419 & 19,44916 & 25,82321 & 0,2762 \\
\hline \multirow{2}{*}{ Chile } & $\mathrm{R}=0$ & $\mathbf{8 3 , 2 5 3 7 9}$ & $\mathbf{6 3 , 8 7 6 1}$ & $\mathbf{0 , 0 0 0 5}$ & $\mathbf{4 1 , 5 2 3 3 5}$ & $\mathbf{3 2 , 1 1 8 3 2}$ & $\mathbf{0 , 0 0 2 7}$ \\
& $\mathrm{R} \leq 1$ & 41,73044 & 42,91525 & 0,0654 & 20,30438 & 25,82321 & 0,2261 \\
\hline \multirow{2}{*}{ Colômbia } & $\mathrm{R}=0$ & $\mathbf{7 4 , 3 1 1 6 1}$ & $\mathbf{6 3 , 8 7 6 1}$ & $\mathbf{0 , 0 0 5 2}$ & $\mathbf{3 4 , 0 6 8 4 6}$ & $\mathbf{3 2 , 1 1 8 3 2}$ & $\mathbf{0 , 0 2 8 5}$ \\
& $\mathrm{R} \leq 1$ & 40,24315 & 42,91525 & 0,0903 & 20,1254 & 25,82321 & 0,236 \\
\hline \multirow{2}{*}{ Coreia do Sul } & $\mathrm{R}=0$ & $\mathbf{7 0 , 8 7 9 8 7}$ & $\mathbf{6 3 , 8 7 6 1}$ & $\mathbf{0 , 0 1 1 5}$ & $\mathbf{3 5 , 5 5 6 7 3}$ & $\mathbf{3 2 , 1 1 8 3 2}$ & $\mathbf{0 , 0 1 8 2}$ \\
& $\mathrm{R} \leq 1$ & 35,32314 & 42,91525 & 0,232 & 21,69888 & 25,82321 & 0,1598 \\
\hline \multirow{2}{*}{ México } & $\mathrm{R}=0$ & $\mathbf{7 6 , 4 0 9 0 4}$ & $\mathbf{6 3 , 8 7 6 1}$ & $\mathbf{0 , 0 0 3 1}$ & $\mathbf{3 7 , 3 8 5 2 9}$ & $\mathbf{3 2 , 1 1 8 3 2}$ & $\mathbf{0 , 0 1 0 3}$ \\
& $\mathrm{R} \leq 1$ & 39,02374 & 42,91525 & 0,1162 & 17,51861 & 25,82321 & 0,415 \\
\hline
\end{tabular}

Fonte: Elaboração própria.

Para se determinar o número de defasagens a serem incluídas no modelo VEC de cada país, realizou-se o teste de seleção do número de defasagens do sistema de equações de Vetores Autorregressivos (VAR), cujos resultados encontram-se na Tabela 4.

Tabela 4 - Seleção de defasagens (VAR) para todos os países

\begin{tabular}{|c|c|c|c|c|c|c|c|}
\hline País & Lag & $\log L$ & LR & FPE & AIC & SC & HQ \\
\hline \multirow{3}{*}{ África do Sul } & 2 & 2022.212 & 465.9307 & $6.84 \mathrm{E}-18$ & -28.17322 & $-27.42034^{*}$ & $-27.86728^{\star}$ \\
\hline & 5 & 2071.257 & 30.33391 & $6.79 \mathrm{e}-18^{*}$ & $-28.18804^{*}$ & -26.43133 & -27.47418 \\
\hline & 7 & 2101.736 & $40.32950^{*}$ & $7.05 \mathrm{E}-18$ & -28.16646 & -25.74053 & -27.18065 \\
\hline \multirow{2}{*}{ Brasil } & 1 & 1233.62 & 263.1114 & $5.62 \mathrm{e}-13^{*}$ & $-16.85583^{\star}$ & $-16.44336^{*}$ & $-16.68823^{\star}$ \\
\hline & 2 & 1247.789 & $26.56608^{\star}$ & $5.77 \mathrm{E}-13$ & -16.8304 & -16.08795 & -16.52871 \\
\hline \multirow{2}{*}{ Chile } & 1 & 1353.922 & 102.3779 & $9.29 \mathrm{E}-14$ & -18.65625 & $-18.24187^{*}$ & $-18.48787^{\star}$ \\
\hline & 3 & 1394.956 & $38.44041^{\star}$ & $8.20 \mathrm{e}-14^{\star}$ & $-18.78260^{*}$ & -17.7052 & -18.34479 \\
\hline \multirow{3}{*}{ Colômbia } & 2 & 2015.357 & 99.58779 & $7.54 \mathrm{E}-18$ & -28.07598 & $-27.32311^{*}$ & $-27.77004^{\star}$ \\
\hline & 3 & 2036.466 & 38.32592 & $7.02 \mathrm{e}-18^{*}$ & $-28.14846^{*}$ & -27.06097 & -27.70654 \\
\hline & 6 & 2076.62 & $26.30324^{\star}$ & $7.95 \mathrm{E}-18$ & -28.03716 & -25.94584 & -27.18732 \\
\hline \multirow{2}{*}{ Coreia do Sul } & 1 & 1928.361 & 314.2696 & $2.06 \mathrm{e}-17^{*}$ & $-27.06895^{*}$ & $-26.65069^{*}$ & $-26.89898^{\star}$ \\
\hline & 7 & 2011.145 & $38.36143^{*}$ & $2.55 \mathrm{E}-17$ & -26.88149 & -24.45556 & -25.89567 \\
\hline \multirow{3}{*}{ México } & 1 & 1600.474 & 482.7998 & 2.95E-15 & -22.10453 & $-21.69015^{\star}$ & $-21.93614^{*}$ \\
\hline & 2 & 1623.961 & 44.01774 & $2.66 \mathrm{e}-15^{\star}$ & $-22.20924^{*}$ & -21.46335 & -21.90615 \\
\hline & 6 & 1681.469 & $33.66787^{*}$ & $2.95 \mathrm{E}-15$ & -22.11845 & -20.04653 & -21.27652 \\
\hline
\end{tabular}

Notas: ${ }^{*}$ Indica o número de defasagens selecionado por cada critério para o sistema VAR; para o sistema VEC, seleciona-se p-1 defasagens. LR: estatística LR; FPE: erro final de previsão; AIC: critério de informação de Akaike; SC: critério de informação de Schwarz; HQ: critério de informação de Hannan-Quinn.

Fonte: Elaboração própria.

Os resultados obtidos são divergentes. A África do Sul mostrou dois critérios com duas e cinco defasagens. O Brasil e a Coreia mostraram quatro critérios com uma defasagem. O Chile mostrou dois e três critérios para uma e três defasagens, respectiva- 
mente. A Colômbia mostrou dois critérios em duas e três defasagens. Por último, o México apresentou o critério em uma e duas defasagens. Esses resultados indicam que os modelos VEC estimados não deveriam incluir nenhuma defasagem para Brasil e Coreia; incluir uma ou quatro para a África do Sul; para o Chile, duas; para a Colômbia, uma e duas; e para o México, nenhuma e uma. Em todo caso, a dinâmica do modelo seria muito pobre com a introdução de apenas uma defasagem. Além disso, seria pouco intuitivo imaginar que os efeitos das políticas monetárias se consumiriam tão rapidamente.

Como a bateria de testes foi inconclusiva, optou-se por estimar os seguintes modelos para cada país: África do Sul - VEC(3); Brasil - VEC(2); Chile - VEC(8); Colômbia - VEC(2); Coreia - VEC(3); e México - VEC(2) ${ }^{11}$. No caso do Chile, como a meta de convergência da inflação é de médio prazo, dois anos, apenas o modelo com oito defasagens apresentou resultados mais significativos.

$\mathrm{Na}$ Tabela 5, são apresentados os principais resultados do teste de causalidade de Granger (estatisticamente significativos) para as variáveis em bloco, muito utilizado para avaliar se determinada variável causa, no sentido de Granger, outra determinada variável.

Tabela 5 - Teste de Causalidade de Granger para todos os países

\begin{tabular}{lllrrr}
\hline País & Variável dependente & \multicolumn{1}{c}{ Excluída } & Chi-sq & df & Prob. \\
\hline \multirow{4}{*}{ Brasil } & D(LNJUROS) & D(LNIPCA) & 7.4075 & 2 & $\mathbf{0 . 0 2 5}$ \\
& & D(LNIND) & 8.626411 & 2 & $\mathbf{0 . 0 1 3}$ \\
& & All & 18.00837 & 6 & $\mathbf{0 . 0 0 6}$ \\
& D(LNIPCA) & D(LNJUROS) & 16.79724 & 2 & $\mathbf{0}$ \\
& & D(LNCAMBIO) & 4.641606 & 2 & $\mathbf{0 . 0 9 8}$ \\
& All & D(LNCAMBIO) & 16.35622 & 2 & $\mathbf{0}$ \\
D(LNIND) & All & 22.82258 & 6 & $\mathbf{0 . 0 0 1}$ \\
\hline \multirow{3}{*}{ Chile } & D(LNJUROS) & All & 41.00561 & 8 & $\mathbf{0}$ \\
& & D(LNIND) & 74.87035 & 24 & $\mathbf{0}$ \\
& \multirow{2}{*}{ D(LNIPC) } & D(LNCAMBIO) & 15.78237 & 8 & $\mathbf{0 . 0 4 6}$ \\
& & All & 39.73826 & 8 & $\mathbf{0}$ \\
& & D(LNJUROS) & 57.24698 & 24 & $\mathbf{0}$ \\
& & D(LNCAMBIO) & 16.99933 & 8 & $\mathbf{0 . 0 3}$ \\
& D(LNIND) & All & 17.23786 & 8 & $\mathbf{0 . 0 2 8}$ \\
& & & 48.00884 & 24 & $\mathbf{0 . 0 0 3}$ \\
\hline
\end{tabular}

${ }^{11}$ Realizaram-se testes dos modelos VEC com número maior de defasagens em cada país, mas os melhores resultados foram esses citados no texto. Os resultados obtidos foram de certa forma mais ajustados, sem perda significativa de graus de liberdade, além de apresentarem um comportamento mais convergente nas funções de impulso-resposta. 
Tabela 5 - Teste de Causalidade de Granger para todos os países

\begin{tabular}{|c|c|c|c|c|c|}
\hline País & Variável dependente & Excluída & Chi-sq & df & Prob. \\
\hline \multirow{2}{*}{ África do Sul } & \multirow{2}{*}{ D(LNJUROS) } & D(LNIND) & 15.07921 & 3 & 0.002 \\
\hline & & All & 27.69961 & 9 & 0.001 \\
\hline \multirow{3}{*}{ Colômbia } & \multirow{3}{*}{ D(LNJUROS) } & D(LNIPC) & 10.71976 & 2 & 0.005 \\
\hline & & D(LNIND) & 8.651164 & 2 & 0.013 \\
\hline & & All & 21.22494 & 6 & 0.002 \\
\hline \multirow{5}{*}{ Coreia do Sul } & \multirow{3}{*}{ D(LNJUROS) } & D(LNIND) & 13.8874 & 3 & 0.003 \\
\hline & & D(LNCAMBIO) & 30.94242 & 3 & $\mathbf{0}$ \\
\hline & & All & 53.59885 & 9 & 0 \\
\hline & \multirow{2}{*}{ D(LNIND) } & D(LNCAMBIO) & 14.02917 & 3 & 0.003 \\
\hline & & All & 24.25407 & 9 & 0.004 \\
\hline \multirow{7}{*}{ México } & \multirow{2}{*}{ D(LNJUROS) } & $\mathrm{D}(\mathrm{LNIPC})$ & 5.513357 & 2 & 0.064 \\
\hline & & All & 12.08185 & 6 & 0.06 \\
\hline & D(LNIPC) & D(LNCAMBIO) & 5.953238 & 2 & 0.051 \\
\hline & D(LNIND) & D(LNCAMBIO) & 7.381547 & 2 & 0.025 \\
\hline & \multirow{3}{*}{ D(LNCAMBIO) } & D(LNIPC) & 4.915075 & 2 & 0.086 \\
\hline & & D(LNIND) & 10.42431 & 2 & 0.005 \\
\hline & & All & 20.12615 & 6 & 0.003 \\
\hline
\end{tabular}

Fonte: Elaboração própria.

Os resultados mais significativos foram obtidos no Brasil, no Chile e no México. Para a finalidade do artigo, o que importa é o que a variável Juros precede. Dessa forma, na África do Sul, Juros precede a variável Ind e todas as variáveis em conjunto; no Brasil e na Colômbia, IPC(A), Ind e todas; no Chile, IPC e todas; na Coreia, Ind, Câmbio e todas; e por último, o México, IPC e todas, relembrando que todas no sentido de Granger. Esses resultados mostram que, na maioria dos casos, há uma forte relação entre taxa de juros e inflação. Mais à frente, esses resultados serão melhor explorados.

Quando se realizaram os sumários dos testes de Johansen houve um indicativo de que todas as equações de cointegração devem ser lineares com intercepto e tendência. Os vetores estimados para cada país estão descritos a seguir, e correspondem à relação de longo prazo entre as variáveis.

Tabela 6 - Vetores de cointegração

\begin{tabular}{lccccc}
\hline \multirow{2}{*}{ País } & \multicolumn{5}{c}{ Vetores de cointegração (normalizado) } \\
& LNJUROS(-1) & C & LNIPC(-1) & LNIND(-1) & LNCAMBIO(-1) \\
\hline \multirow{3}{*}{ África do Sul } & $\mathbf{1}$ & $\mathbf{9 1 . 7 5}$ & $\mathbf{5 . 9 8 8}$ & $\mathbf{- 2 4 . 1 3 4}$ & $\mathbf{- 6 . 2 6 4 5}$ \\
& - & - & $(-1.671)$ & $(-6.130)$ & $(-1.414)$ \\
& - & - & {$[3.582]$} & {$[-3.936]$} & {$[-4.429]$} \\
\hline \multirow{2}{*}{ Brasil } & $\mathbf{1}$ & $-\mathbf{1 4 . 0 7 3}$ & $\mathbf{0 . 6 0 5 6}$ & $\mathbf{2 . 3 4 8}$ & $\mathbf{- 1 , 0 1}$ \\
& - & - & $(-0,213)$ & $(-0,757)$ & $(-0,369)$ \\
& - & - & {$[2.839]$} & {$[3.101]$} & {$[-2.730]$} \\
\hline
\end{tabular}


Tabela 6 - Vetores de cointegração

\begin{tabular}{|c|c|c|c|c|c|}
\hline \multirow{2}{*}{ País } & \multicolumn{5}{|c|}{ Vetores de cointegração (normalizado) } \\
\hline & LNJUROS(-1) & C & LNIPC(-1) & $\operatorname{LNIND}(-1)$ & $\operatorname{LNCAMBIO}(-1)$ \\
\hline & 1 & -33.123 & 9.4488 & -5.114 & 1.9197 \\
\hline \multirow[t]{3}{*}{ Chile } & - & - & $(-5.115)$ & $(-4.631)$ & $(-1.101)$ \\
\hline & - & - & {$[1.847]$} & {$[-1.104]$} & {$[1.743]$} \\
\hline & 1 & 14.648 & 5.802 & -7.506 & -1.256 \\
\hline \multirow[t]{3}{*}{ Colômbia } & - & - & $(-0,930)$ & $(-1.607)$ & $(-0,582)$ \\
\hline & - & - & {$[6.236]$} & {$[-4.669]$} & {$[-2.158]$} \\
\hline & 1 & -93.847 & 36.317 & -14.345 & $-0,641$ \\
\hline \multirow[t]{3}{*}{ Coreia do Sul } & - & - & $(-5.392)$ & $(-2.275)$ & $(-0,782)$ \\
\hline & - & - & {$[6.734]$} & {$[-6.304]$} & {$[-0,819]$} \\
\hline & 1 & -3.582 & $-0,111$ & -1.064 & 2.933 \\
\hline \multirow[t]{2}{*}{ México } & - & - & -1.387 & -2.011 & -1.25 \\
\hline & - & - & {$[-0,080]$} & {$[-0,529]$} & {$[2.345]$} \\
\hline
\end{tabular}

Nota: Desvio padrão entre parênteses; estatística t entre colchetes.

Fonte: Elaboração própria.

Essas equações de cointegração poderiam ser interpretadas como uma função de reação de cada banco central no longo prazo. As equações foram normalizadas para a variável Juros, o que pode comprometer a interpretação da magnitude dos coeficientes estimados. Contudo, o que interessa saber aqui é que Juros são tratados como uma variável endógena que depende, diretamente e positivamente, de três variáveis: inflação, nível de atividade econômica e taxa de câmbio.

No RMI, a variável Câmbio é importante como forma de induzir a baixa dos preços dos produtos internamente, além de se constituir em um mecanismo de promoção do crescimento econômico muito utilizado por alguns países. Em síntese, os sinais dos parâmetros das equações são condizentes com os resultados obtidos.

\section{EFICÁCIA DO RMI NOS PAÍSES SELECIONADOS (2000-2012)}

Nesta seção pretende-se verificar a eficácia da política monetária nos países selecionados, isto é, analisar se o RMI, que opera via o instrumento taxa de juros, é efetivo na redução do nível de preços nesses países. Para tal, serão analisadas as respostas das variáveis IPC a um choque (de um desvio padrão e segundo a decomposição de Cholesky) na variável Juros. Dessa forma, é possível observar os efeitos sobre o nível de preços da elevação dos juros nos países que adotam esse mecanismo. A resposta dos índices de inflação às elevações nas taxas de juros varia de país para país, mas notam-se algumas semelhanças, conforme mostra a Figura 1: 
Figura 1 - Funções de Impulso Resposta (FIR)
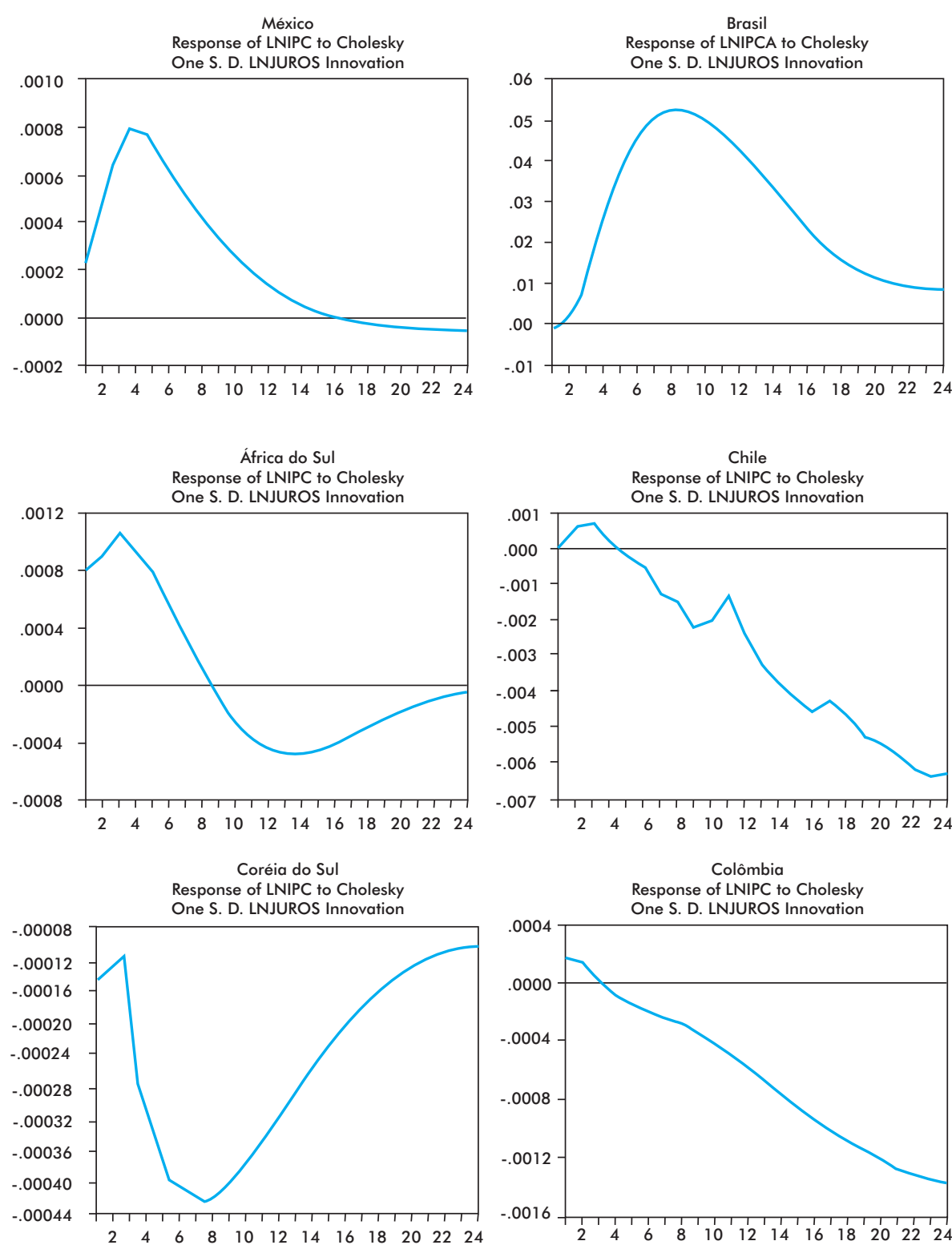

Fonte: Elaboração própria. Saída do Eviews.

Conforme se observa na Figura 1, há quatro padrões de resposta dos índices de preços a uma elevação da taxa de juros. O primeiro padrão está presente na África do Sul e no México, em que uma elevação da taxa de juros responde com uma elevação 
rápida no índice de preços, seguida de sua redução para um patamar inferior ao verificado no início, de cinco meses para a África do Sul e de nove meses para o México. No caso da África do Sul, verifica-se que a resposta a um aumento dos juros torna o índice de preços negativo no nono período, enquanto que no México esse efeito ocorre apenas no décimo sexto período.

O outro padrão evidencia-se com Chile e Colômbia. Em ambos os países, a resposta dos índices de preços se mostra mais rápida que no padrão observado anteriormente. A origem da resposta imediata do Chile se dá na origem dos eixos, enquanto que a da Colômbia se dá positivamente, mas rapidamente os índices de inflação cedem, entrando em trajetória declinante, e tornando-se negativa com quatro meses para a Colômbia e cinco meses para o Chile.

O terceiro padrão observável é o do Brasil. Entre todos os casos analisados, o Brasil é o único em que a resposta do índice de preços a um aumento dos juros não vem a ser negativa após 24 períodos e a resposta torna-se declinante apenas após nove períodos, o maior entre todos os países analisados. Isso evidencia que o Brasil tem a pior resposta de política monetária entre os países da amostra.

Por fim, a política monetária no caso da Coreia do Sul mostra-se a mais efetiva entre os países analisados. A origem da resposta se dá negativamente e se amplia até o sétimo período, voltando a se tornar positivamente inclinada, mas permanecendo negativa mesmo após 24 períodos.

Os resultados contra intuitivos obtidos na África do Sul, no Brasil e no México, em que um choque contracionista de política monetária é sucedido por uma elevação inicial da inflação, evidenciam o fenômeno que ficou conhecido na literatura como price puzzle ${ }^{12}$. Essa correlação positiva entre a taxa de inflação e a taxa de juros nominal tem sido objeto constante de estudo no meio acadêmico, uma vez que não encontra respaldo na teoria econômica tradicional. No entanto, a maioria desses estudos tem se concentrado nas economias desenvolvidas.

De modo geral, os trabalhos realizados em busca de uma "solução" para o price puzzle podem ser classificados em três grupos distintos. Para o primeiro, esse comportamento seria fruto de problemas de má identificação na estimação dos modelos VAR: as variáveis incluídas no modelo não esgotam o conjunto de informação à disposição do Banco Central (SIMS, 1992). Contudo, essa justificativa não cabe à presente pesquisa, uma vez que o modelo utilizado é o VEC e não o VAR, origem da controvérsia em diver-

\footnotetext{
12 O ponto de partida desse fenômeno é o artigo de Sims (1992), embora o termo "price puzzle" só tenha sido cunhado posteriormente por Eichenbaum (1992), em comentário ao artigo de Sims.
} 
sos estudos ${ }^{13}$. Ao contrário do VAR, o VEC é um modelo que evidencia uma relação de longo prazo das variáveis analisadas. Dessa forma, não há evidencia de que seja um problema de especificação dos modelos estimados. O segundo grupo, por seu turno, questiona a teoria convencional no âmbito dos efeitos de uma contração monetária não antecipada pelos agentes econômicos. Nesse sentido, a elevação dos preços em resposta à contração monetária inesperada decorreria da existência de outro canal de transmissão da política monetária, um canal de custos, que operaria através da oferta agregada. Basicamente, conforme Modenesi, Pires-Alves e Martins (2012), o modus operandi do canal de custos é o seguinte: um aumento da taxa de juros eleva o custo de produção das firmas que, dependendo de seu poder de mercado e das condições de demanda, pode ser repassado aos preços. Com isso, num primeiro instante, uma contração monetária gera um aumento de custos que se transmite mais rapidamente para os preços. Num segundo momento, uma elevação dos juros desaquece a economia e, finalmente, impacta negativamente a inflação. O puzzle surgiria, portanto, de um descompasso entre os efeitos da política monetária sobre os custos de produção, que são mais imediatos, e seus impactos defasados sobre a demanda agregada e, por fim, nos preços. Por fim, um terceiro grupo, em especial para o caso brasileiro, assume que o price puzzle adviria de um possível efeito riqueza financeira às avessas, em que detentores de títulos públicos indexados à Selic não sentiriam efeitos de uma política monetária restritiva, tendo um efeito inverso, o que tornaria esses indivíduos mais "ricos" com a posse desses títulos (MODENESI e MODENESI, 2012). Esse efeito mostra claramente uma obstrução do canal de transmissão da política monetária em que um aumento da taxa de juros deveria refletir uma perda de poder aquisitivo dos agentes detentores de títulos públicos, mas em que, na verdade, há um aumento de poder aquisitivo por parte desses agentes (BARBOZA, 2015).

Portanto, nota-se que à exceção da África do Sul, do Brasil e do México, os outros

três países analisados possuem uma política monetária mais eficiente no controle inflacionário. Esses resultados corroboram, em parte, os argumentos de que regimes de metas de inflação mais flexíveis são preferíveis àqueles mais rígidos, tendo-se ainda em vista os impactos potenciais dos últimos sobre o produto.

\section{CONCLUSÃO}

Dentro do regime de metas de inflação adotado por diversos países, entre eles o Brasil, a taxa básica de juros é o principal instrumento utilizado pelo Banco Central para o controle inflacionário. Assim, o controle dos preços é feito via elevações na taxa de

\footnotetext{
13 Ver Giordani (2004); Hanson (2004); Li, Pereira e Shields (2013); Rusnak; Havranek e Horváth (2013).
} 
juros, que através dos canais de transmissão da política monetária afetam a demanda agregada e os preços internacionais e, assim, atingem a inflação. Logo, esse regime pressupõe que a inflação é um fenômeno tipicamente de demanda, a qual deve ser combatida pelo emprego de política monetária contracionista, em especial, com aumentos na taxa de juros básica.

Dessa forma, o regime negligencia outras causas do processo inflacionário, especialmente aquelas ligadas ao lado da oferta da economia, como a inflação de salários e lucros; a inflação importada; a inflação oriunda de choques de oferta; a inflação de impostos; e a existência de algum grau de inércia na taxa de inflação.

A experiência brasileira e de outros países no controle de preços sob o regime de metas de inflação evidencia, entretanto, que a inflação nem sempre é oriunda de choques de demanda, de modo que a utilização da taxa juros, na maioria das vezes, não ataca a real causa da inflação, mas apenas seus sintomas.

Além disso, as elevações das taxas de juros para conter o ímpeto inflacionário na economia podem resultar em efeitos nocivos quanto à estagnação da renda, o aumento do deficit público, a apreciação da taxa de câmbio e o aumento do hiato do emprego, levando a economia a se manter em um estado permanente de stop and go.

Essas constatações levam à essência das recomendações de política baseadas na experiência brasileira e internacional de adoção do regime de metas de inflação como estratégia de controle de preços. A primeira delas é que o controle de preços não deve utilizar única e exclusivamente as elevações na taxa de juros para conter a inflação e a segunda é que uma institucionalidade do regime que garanta certo grau de flexibilidade ao modelo pode levar a melhores resultados em termos de crescimento econômico.

Nesse contexto, a principal conclusão deste artigo é a de que, comparativamente, o RMI brasileiro é menos efetivo do que o dos outros países emergentes selecionados. Uma possível explicação pode ser atribuída ao regime bastante rígido implantado em 1999, mas que, segundo alguns autores ${ }^{14}$, deveria ser flexibilizado, como fizeram a Coreia do Sul e o Chile. Um bom exemplo de flexibilização do RMI é a Coreia do Sul, que começou o regime usando o índice de preços cheio, alterando posteriormente para o núcleo, com a exclusão de preços de alimentos e de energia. Outros fatores importantes são os horizontes de convergência das metas estipuladas, que, exceto no Brasil e na África do Sul, são todos maiores ou iguais a dois anos. Esses horizontes maiores são coerentes, uma vez que há certa defasagem temporal para a política monetária surtir efeito sobre os agentes econômicos.

\footnotetext{
14 Ver Giambiagi e Velho (2004); Giambiagi, Mathias e Velho (2006); Modenesi (2010, 2011); Modenesi e Ferrari-Filho (2011); Modenesi e Modenesi (2012).
} 
Além disso, alguns trabalhos ${ }^{15}$ já evidenciaram que no Brasil a inflação possui baixa sensibilidade a mudanças nas taxas de juros, sendo mais influenciada por outras variáveis, como o câmbio, por exemplo. Isso não significa que quando se trata de política monetária, a flexibilização do regime, por si só, constitui-se em uma panaceia para os problemas existentes no Brasil, uma vez que há outros fatores importantes que merecem atenção e estão intimamente ligados à rigidez da política monetária, como a indexação de vários preços da economia, elevado número de preços administrados influenciando o IPCA e títulos da dívida indexados à Selic.

\section{REFERÊNCIAS}

ALESINA, A.; GATTI, R. Independent central banks. American Economic Review, v. 85, n. 2, mai.1995.

ALESINA, A.; SUMMERS, L. Central Bankin dependence and macroeconomic performance: some evidence. Journal of Money Credit and Banking, v. 25, n. 2, mai.1993.

AMSDEN, A. Asia's next giant: South Korea and late industrialization.Oxford: Oxford University Press, 1989.

BANCO CENTRAL DA ÁFRICA DO SUL. Disponível em: <http://www.reservebank.co.za/> .

BANCO CENTRAL DA COLÔMBIA. Disponível em: <http://www.banrep.gov.co/>.

BANCO CENTRAL DA COREIA DO SUL. Disponível em: <http://www.bok.or.kr/eng/index.jsp >.

BANCO CENTRAL DA MÉXICO. Disponível em: <http://www.banxico.org.mx/>.

BANCO CENTRAL DO BRASIL. Disponível em: <http://www.bcb.gov.br $>$.

BANCO CENTRAL DO CHILE. Disponível em: <http://www.bcentral.cl/index.asp >.

BARBOZA, R. M. Taxa de juros e mecanismos de transmissão da política monetária no Brasil. Revista de Economia Política, v. 35, n. 1, p. 133-155, 2015.

BERNANKE, B. S.; MISHKIN, F. S. Inflation targeting: a new framework for monetary policy. Journal of Economic Perspectives, v. 11, n. 2, p. 97-116, 1997.

BOYER, P.; PONCE, J. Central Banks, regulatory capture and banking supervision reforms. Paolo Baffi Centre Research Paper, n. 2010-83, 2010.

BRESSER-PEREIRA, L. C.; GOMES, C. "O regime de metas de inflação no Brasil e a armadilha da taxa de juros/taxa de câmbio". In: OREIRO, J. L.; PAULA, L. F.; SOBREIRA, R. (Orgs.) Política monetária, bancos centrais e metas de inflação: teoria e experiência brasileira. Rio de Janeiro: FGV, 2009, p. 21-51.

BRESSER-PEREIRA, L. C. O novo desenvolvimentismo e a ortodoxia convencional. São Paulo em Perspectiva, v. 20, n. 3, p. 5-24, 2006.

15 Modenesi e Araújo (2009, 2011). 
BUENO, R. Econometria de séries temporais. 2. ed. São Paulo: Cengage Learning, 2011.

CAMPBELL, J. Y.; PERRONP. Pitfalls and opportunities: what macroeconomists should know about unit roots and cointegration. NBER Macroeconomics Annual, Cambridge, MA: MIT Press, 1991.

CANOVA, T. A. Banking \& Financial Services Policy Report, p. 11-25, nov. 2011.

CHANG, H.J. Chutando a escada: a estratégia do desenvolvimento em perspectiva histórica. Revista de Economia Política, v. 26, p. 4, 2006.

CUKIERMAN, A. Central Bank independence and monetary control. The Economic Journal, nov. 1994.

CUKIERMAN, A. Central Bank strategy, credibility and independence: theory and evidence. Cambridge: MTI Press, 1992.

EICHENGREEN, B. et al. Transition strategies and nominal anchors on the road to greater exchange-rate flexibility. Essays in International Finance, Princeton, v. 213, 1999.

ELLIOTT, G.; ROTHENBERG, T. J.; STOCK, J. H. Efficient tests for an autoregressive unit root. Econometrica, v. 64, p. 813-836, 1996.

ENDERS, W. Applied econometric times series. 2. ed. Nova York: John Wiley \& Sons, Inc., 1995.

ENGEL, R. F.; GRANGER, C. W. J. Co-integration and error correction: representation, estimation, and testing. Econometrica, n. 55, p. 251-276, 1987.

FARHI, M. Análise comparativa do regime de metas de inflação: pass-through, formatos e gestão nas economias emergentes. Texto para Discussão, Instituto de Economia, Unicamp, Campinas, n. 127, jul. 2007.

GIAMBIAGI, F.; MATHIAS, A.; VELHO, E. O aperfeiçoamento do regime de metas de debate inflação no Brasil. Economia Aplicada, v. 10, n. 3, set. 2006.

GIAMBIAGI, F.; VELHO, E. Uma proposta de aperfeiçoamento do sistema de metas de inflação: o uso do IPCA médio de 12 meses Boletim de Conjuntura IPEA, Nota Técnica, jun. 2004.

GIORDANI, P. An alternative explanation of the price puzzle. Journal of Monetary Economics, v. 51, n. 6, p. 1271-1296, 2004.

GOODHART, C. A. What should Central Banks Do? What should be their macroeconomic objectives and operations? The Economic Journal, p. 1424-36, nov. 1994b.

GREENE, W. H. Econometric Analysis. 7. ed. New Jersey: Pearson Prentice Hall, 2011.

HANSON, M. S. The "price puzzle" reconsidered. Journal of Monetary Economics, v. 51, n. 7, p. 1385-1413, 2004.

IBGE - INSTITUTO BRASILEIRO DE GEOGRAFIA E ESTATÍSTICA. Disponível em: <www. ibge.gov.br>.

IMF - INTERNATIONAL MONETARY FUND. International Financial Statistics Yearbook. Washington: IMF, 2012. Disponível em: <http://www.imf.org/external/index.htm $>$.

IPEADATA. Disponível em: <www.ipeadata.gov.br >.

JOHANSEN, S; JUSELIUS, K. Maximum likelihood estimation and inferences on cointegration - with applications to the demand for money. Oxford Bulletin of Economics and Statistics, $\mathrm{n}$. 52, p. 169-210, 1990. 
JOHANSEN, S. Statistical analysis of cointegration vectors. Journal of Economic Dynamics and Control, v. 12, p. 231-254, 1988.

LI, S. M.; PERERA, R.; SHIELDS, K. Misspecification, identification or measurement? Another look at the price puzzle. 2013. Disponível em: <http://econpapers.repec.org/scripts/redir. pf? u =http $\% 3$ A $\% 2$ F\%2Ffbe.unimelb.edu.au\%2F_data\%2Fassets\%2Fpdf_ file\%2F0011\%2F796970\%2F1169.pdf;h=repec:mlb:wpaper:1169>.

MASIERO, G. "A economia coreana: características estruturais". In: GUIMARÃES, S. P. (Org.). Coreia: visões brasileiras. Brasília: Instituto de Pesquisa de Relações Internacionais, 2002, p. 199-252.

MISHKIN, F. S. Inflation targeting in emerging-market countries. The American Economic Review, v. 90, n. 2, p. 105-109, 2000.

MISHKIN, F. S. International experiences with different monetary policy regimes. NBER Working Paper, n. 7044, Mar. 1999.

MODENESI, A. M. Conservadorismo e rigidez na política monetária: uma estimativa da função de reação do BCB (2000-2007). Revista de Economia Política (Impresso), v. 21, p. 79-98, 2011.

MODENESI, A. M. Política Monetária no Brasil pós Plano Real (1995-2008): um breve retrospecto. Economia \& Tecnologia, v. 21, p. 21-30, 2010.

MODENESI, A. M. Regimes Monetários: teoria e experiência do real. Barueri: Manole, 2005.

MODENESI, A. M.; ARAÚJO, E. C. Price stability under inflation targeting in Brazil: an empirical analysis of the monetary policy transmission mechanism based on a VAR model. Texto para Discussão, Instituto de Economia, UFRJ, Rio de Janeiro, n. 3, 2012.

MODENESI, A. M.; ARAUUJO, E. C. Costs and benefits of inflation control in Brazil (2000-2008): an empirical analysis of the monetary policy transmission mechanism based on a VAR model. In: INTERNATIONAL CONFERENCE DEVELOPMENTS IN ECONOMIC THEORY AND POLICY, 8, Bilbao, Espanha, 2011.

MODENESI, A. M.; FERRARI FILHO, F. Choque de oferta, indexação e política monetária: breves considerações. Economia \& Tecnologia, v. 26, p. 5-13, 2011.

MODENESI, A. M.; MODENESI, R. L. Quinze anos de rigidez monetária no Brasil pós-Plano Real: uma agenda de pesquisa. Revista de Economia Política (Impresso), v. 32, p. 389-411, 2012.

MODENESI, A. M.; PIRES-ALVES, C. C.; MARTINS, M. N. Mecanismo de transmissão da política monetária: a importância dos fatores microeconômicos. Oikos, v. 11, p. 203-216, 2012.

MODENESI, A. M.; ARAÚJO, E. C. de. Custos e benefícios do controle inflacionário no Brasil (2000-2008): uma avaliação com base em um Modelo VEC. In: ENCONTRO INTERNACIONAL DA ASSOCIAÇÃO KEYNESIANA BRASILEIRA, 2, Porto Alegre / RS, 2009.

PARREIRAS, M. A. A estrutura institucional da dívida pública brasileira e seus impactos sobre a gestão da política monetária: uma análise empírica do regime de metas para a inflação. Dissertação (Mestrado), Universidade de São Paulo, São Paulo, 2007.

PHILLIPS, P. PERRON, P. Testing for a unit root in time series regression. Biometrika, 75, 33546, 1988. 
ROCHA, M.; OREIRO, J. L. A experiência internacional de regimes de metas de inflação: uma análise com painel dinâmico. Nova Economia, Belo Horizonte, n. 18, v. 2, p. 267-291, mai./ ago. 2008.

ROGOFF, K. The Optimal degree of commitment to an intermediate monetary target. Quarterly Journal of Economics, p. 1169-89, nov. 1985.

RUSNÁK, M.; HAVRANEK, T.; HORVÁTH, R. How to solve the price puzzle? A meta-analysis. Journal of Money, Credit and Banking, v. 45, n. 1, p. 37-70, 2013.

SIMS, C. Interpreting the macroeconomic time series facts: the effects of monetary policy. European Economic Review. v. 36, p. 975-1000, 1992.

SQUEFF, G. C; OREIRO, J. L.; PAULA, L. F. de. "Flexibilização do regime de metas de inflação em países emergentes: uma abordagem pós-keynesiana”. In: OREIRO, J. L.; PAULA, L. F; SOBREIRA, R. (Eds.). Política monetária, bancos centrais e metas de inflação: teoria e experiência brasileira. Rio de Janeiro: Editora FGV, 2009.

WALSH, C. Optimal contracts for central bankers. The American Economic Review, v. 85, n. 1, p. 150-67, 1995.

WICKSELL, K. The influence of the rate of interest on prices. Economic Journal, n. 17, p. 213-20, Jun. 1907.

WOOLDRIDGE, J. M. Econometric analysis of cross section and panel data. Cambridge, MA: MIT Press, 2002. 